\title{
ADELA CORTINA: EL RETO DE LA ÉTICA CORDIAL
}

\author{
Javier Sánchez Pachón \\ I.E.S. Ciudad de Haro, La Rioja
}

RESUMEN: La ética cordial es la más reciente contribución de Adela Cortina a la Filosofía Moral en España. La cordialidad es una categoría moral sobre la que se puede levantar todo el edificio ético, desde su fundamentación hasta la aplicación práctica. Intentar dar razón de esa cordialidad, fundamentarla desde la antropología como exclusividad humana, caracterizarla desde diferentes ángulos, remitirnos a sus antecedentes filosóficos, concretar las implicaciones que tiene para la obligación moral y apuntar las consecuencias que pueden extraerse de todo ello nos ayudará a considerar la ética desde una perspectiva nueva.

Palabras clave: Cortina, ética, cordialidad, categoría moral, perspectiva.

\section{ADELA CORTINA. THE CHALENGE OF CORDIAL ETHICS}

ABSTRACT: The Ethics to Cordial Reason is the most recent contribution to Moral Philosophy in Spain by Adela Cortina. The cordial reason is a moral category on which the whole ethical building form its foundations to practical application can be lifted. Try to give meaning to this cordiality, base it on anthropology as exclusively human, characterize it from different angles, refer to its philosophical background, determine the implications for moral obligations and draw consequences elicited from all of them will enable to consider Ethics from a new perspective.

Keywords: Cortina, ethics, cardiolity, moral category, perspective. 


\section{La cordialidad}

Adela Cortina es la principal representante de la que comienza a llamarse Escuela de Valencia: un grupo de investigadores, sobre todo profesores de Filosofía Moral, que ejercen su magisterio en la Universidad de Valencia y en la Universidad de Castellón y que llevan unos años realizando un gran trabajo de organización de congresos, conferencias, publicaciones e incluso fundaciones en los que aparece la ética práctica aplicada a los ámbitos que la sociedad civil reclama: política, religión, economía, educación, empresa, investigación, medicina, ecología...

Así, podríamos decir que Cortina, como otros filósofos actuales en España, ha bajado la ética del mundo ideal platónico a la calle y a la ciudad, y la ha animado no a imponerse sino a convivir con otras realidades, unas aparentemente muy diferentes como el consumo o la empresa, otras muy cercanas desde siempre como la política, la religión o la sociedad civil.

Su libro Ética mínima (1987) marca el inicio de una visión de la ética que continúa la estela de Ortega, Zubiri y Aranguren en lo que se refiere a la fundamentación antropológica de los móviles morales. Cortina en obras posteriores planteará la búsqueda de los mínimos éticos con el procedimiento hermenéutico de la ética discursiva de Apel y Habermas, pero veinte años después, en 2007, Adela Cortina completará su visión de la moral con un libro titulado Ética de la razón cordial en el que recurre al concepto de cordialidad como una nueva categoría moral que cerraría la pretendida fundamentación de la moralidad. Es entonces cuando podemos hablar de razones cordiales como integradoras de la moralidad humana.

Ética de la razón cordial lleva como subtítulo educar en la ciudadanía del siglo XXI, con lo que parece que Cortina vuelve a la visión ética que ya hemos mencionado y que descansa en sus antecesores Ortega, Zubiri o Aranguren: la forja de un carácter y no la indoctrinación en unos principios ${ }^{2}$.Y es que la ética no puede convertirse en un catálogo de principios que luego se materializan en normas de comportamiento. Es necesario retomar la ética en su sentido más originario, como una forma continuada de hacer, de comportarse y de estar en el mundo. Como una manera de ajustar el quicio vital, el eje sobre el que la vida

1. Este artículo está elaborado a partir de la tesis doctoral que con el título La razón cordial y la fundamentación ética. Un estudio sobre la obra de Adela Cortina, defendí en la Universidad de La Rioja en mayo de 2014 bajo la dirección de José María Aguirre. Su texto completo está disponible en la página web de las tesis defendidas en la UR y puede consultarse libremente.

En la defensa un miembro del tribunal preguntó qué era en definitiva la razón cordial. Por razones de espacio y tiempo, coordenadas ineludibles al fin y al cabo sobre las que hemos de situar nuestras tareas, no había forma de responder a la pregunta como no fuera remitiendo a la tesis en su conjunto. Sirva el presente artículo para responder y acercar la cordialidad si cabe más a la razón y dibujar así el paisaje sobre el que se fija el horizonte ético de A. Cortina.

2. CORTINA, A. Ética de la Razón Cordial, Ediciones Nobel, Oviedo, 2009, p. 11. 
humana debe girar. La racionalidad encuentra los motivos de actuación humanos, digamos las virtudes, pero es necesario todavía un paso más, las virtudes no sólo hay que conocerlas sino también quererlas, apreciarlas como algo valioso, ¿de qué nos sirve conocer, si el corazón se queda atrás?, se preguntaba Gracián. Pues bien, la cordialidad es para Cortina el combustible del vuelo que la ética pretende realizar sobre la naturaleza y la convivencia humana.

La ética cordial trata de superar así las limitaciones de la ética mínima y salir con ello de una especie de provincianismo ético que toma la razón casi en exclusiva como herramienta y procedimiento. Con la razón cordial se atiende a la constitución integral del ser humano, se atiende, podríamos decir, al corazón de las razones de la obligación moral porque "existe un abismo entre las declaraciones y las realizaciones al hablar de principios y valores morales. Parece que las primeras no calan en la entraña de los seres humanos, que no traspasen del decir, de los labios, que no lleguen al corazón. ¿Cuál es la razón de este abismo entre declaraciones y realizaciones?"3. La ética cordial pretende explicar este abismo entre lo dicho y lo hecho, entre ideas y creencias, actuaciones y declaraciones, entre moral pensada y moral vivida.

Por eso Cortina cree que la ética, además de fundamentarse y de dotarse de una herramienta en la búsqueda de la verdad, debe apuntalarse en las razones del corazón que son las que nos van a mover a preferir unas cosas a otras y nos van a crear un vínculo imprescindible entre lo que queremos hacer y lo que debemos hacer, un vínculo basado en el reconocimiento recíproco y en la lealtad entre los seres que son fines en sí mismos. Con ello Cortina cierra el círculo que había iniciado en la fundamentación ética con la autonomía kantiana volviendo quizá al punto de partida inicial. Desde aquí podríamos nuevamente continuar la andadura ética en esta espiral marcada por la capacidad de darnos nuestras propias normas, la posibilidad de llegar a acuerdos justos y escuchar las razones del corazón que a fin de cuentas es donde se encuentra, como decimos, el corazón de las razones.

Este artículo pretende reunir las principales características de la cordialidad como esa nueva categoría que quiere recuperar la perspectiva etimológica y originaria de la ética. Descubrir las caras principales de la poliédrica razón cordial que conformarían una, si no nueva, sí diferente, forma de enfrentarse el ciudadano del siglo XX al reto de la convivencia justa y felicitante. Por eso vamos a tratar de definir la razón cordial acudiendo a las características bajo las que podemos mirarla. De esa forma podemos también distinguirla de lo que no es, sobre todo para no reducir la ley moral al Pepito Grillo tan subjetivo que nadie toma en serio, o a la tan disfrazada conciencia moral que resulta irreconocible entre los deseos, los instintos, las emociones, las aspiraciones... del ser humano.

Por otra parte, Adela Cortina recoge el testigo de la tradición española pero también de la tradición ética que desde Kant reclama un fundamento para la ética basado en la dignidad del ser humano. En la Historia de la filosofía muchos

3. Ibídem, p. 48. 
han sido los filósofos que han profundizado en este aspecto, este artículo pretende también referirse a algunos de ellos y descubrir las similitudes y las diferencias que se pueden establecer.

Consideraremos aquí la razón cordial desde las siguientes perspectivas: en primer lugar como vínculo intrasubjetivo entre humanos, esto nos llevará a considerarla como compromiso con el otro, después trataremos definirla desde la antropología como ley natural y no artificiosa, también estudiaremos su lado creativo y educativo $y$, finalmente, la veremos en su vertiente social y política. Terminamos con una valoración final de esta forma un tanto novedosa de concebir no sólo el fundamento, sino también la proyección práctica de la moralidad.

\section{El vínculo}

En primer lugar la cordialidad desde una perspectiva antropológica se puede caracterizar como ese vínculo exclusivamente humano que se manifiesta por reconocer a los otros como miembros de la misma "familia": "Toda sociedad opera según el ritmo de dar y recibir. Pero ¿en qué tipo de vínculo, de ligatio, descansa la obligación moral, en todo su amplio sentido?... ¿ de dónde pretenden las leyes morales sacar su fuerza normativa?" ${ }^{\prime 4}$. Esta es la gran pregunta a la que la ética cordial tiene que responder y Cortina lo hace tomando como referencia la historia que el escritor de ciencia-ficción H.G. Wells nos presenta en La isla del doctor Moreau ${ }^{5}$. Esta novela ilustra con una fábula la esencia y los límites de la naturaleza humana; en ella un evolucionista pretende convertir aceleradamente en humanos a los animales con una especie de indoctrinación sobre las virtudes de la humanidad que, siguiendo a Kant, logra sus ventajas sobre los demás seres al tener autonomía y darse sus propias leyes. La experiencia fracasa, pues los animales terminan matando a su mentor y volviendo a su estado selvático. A Cortina le sirve esta anécdota para indagar las razones por las que el experimento ha fracasado y presentarlas como ejemplos de las diversas teorías filosóficas sobre la moral social desde Hobbes a la ética dialógica.

Pero Cortina va más allá a la hora de interpretar el experimento fallido:

El reconocimiento recíproco y cordial es el vínculo, la ligatio que genera una obligatio con las demás personas y consigo mismo, un reconocimiento que no es sólo lógico, sino también compasivo. Con los seres no humanos, cuando son valiosos y vulnerables y pueden ser protegidos, no hay reconocimiento recíproco, claro está, pero sí un aprecio de lo valioso que genera una obligación de responsabilidad. ${ }^{6}$

\footnotetext{
4. Ibídem, p. 49.

5. WELLS, H. G. La isla del doctor Moreau, Anaya, Madrid, 1996.

6. CORTINA, A. Ética de la Razón Cordial, o. c., p. 51.
} 
Para Cortina será, pues, el reconocimiento cordial la diferencia que marque la frontera entre naturaleza animal y naturaleza humana y la fuente de la obligación moral. Estamos así asistiendo, según Cortina, al nacimiento de la moral en el establecimiento de ese vínculo que nos liga indefectiblemente a responder a una exigencia de corresponder.

Encontramos en ello una similitud entre esta teoría del origen de la obligación moral y la del origen de la sociedad que Levi-Strauss anunciara como el principio de reciprocidad: Para Cortina el concepto clave del fundamento de la ética es el de obligación, concepto que tiene para ella un significado no habitual o cuando menos olvidado, porque aunque obligación y deber son sinónimos, la obligación en su etimología apela "al reconocimiento de un vínculo, de una ligación, de una ligatio, de la que se sigue una obligatio, y entonces la obligación puede ser un deber, es decir, la respuesta a una exigencia, o bien el regalo que hace quien se sabe y siente ligado a otro. Sin ese reconocimiento del vínculo, el deber o el regalo carecen de sentido ${ }^{\prime 7}$.

Tenemos así que con el reconocimiento cordial se aclara la base de la obligación ética. El fin en sí mismo kantiano se perfila ahora como "el otro yo" que me completa o sin el cual no puedo ser "yo mismo". Por eso encontramos aquí una estrecha relación con la teoría de Lévinas, para quien tenemos un gran vínculo con los demás porque son parte de nosotros, una ligatio que se convierte en obligatio Este es el gran vínculo sin el que los demás son imposibles: "Quiero decir que una vida en verdad humana no puede quedarse en vida satisfecha en el seno de su igualdad al ser, vida de quietud. Que se despierte hacia el otro, es decir, tiene siempre que desembriagarse ${ }^{\prime \prime}$.

De forma que el mismo Lévinas sugiere que se produce entre los humanos una especie de filiación como la producida entre padre e hijo. Veamos esto porque creemos que es muy esclarecedor sobre lo que supone el reconocimiento recíproco como algo más allá de lo posible:

La paternidad es una relación con un extraño que, aún siendo el otro, es yo. La relación del yo con un yo-mismo que es, sin embargo, extraño a mí. En efecto, el hijo no es simplemente mi obra, como un poema o como un objeto fabricado, no es tampoco mi propiedad... Yo no tengo a mi hijo, yo soy, de alguna manera, mi hijo. Tan solo que aquí las palabras yo soy tienen una significación diferente de la significación eleática o platónica. Hay una multiplicidad y una trascendencia en ese verbo existir... Es un existir pluralista9

Los estoicos fueron quizá los primeros que defendieron con ahínco la pertenencia humana a un Logos universal del que participaban todos, el cristianismo abundó en la idea de igualdad remitiéndonos a los hombres al mismo Padre.

7. Ibídem, p. 46.

8. LÉVINAS, E. Ética e infinito, A. Machado Libros, Madrid, p.103.

9. LÉVINAS, E. De Dios que viene a la idea, Caparrós eds., colección Esprit, Madrid, 1995, pp. 86-87. 
Kant reforzó la idea de autonomía y de universalización de las normas morales. Eso nos haría personas, fines en sí mismos, valiosos y dignos, con lo que la tradición histórico-filosófica apunta a un hecho esencial y sustancial y no diferencial: la especie humana, como especie integrada por seres diferentes en cuanto que son únicos, aunque sobre ella pesa más el hecho de ser humanos que el hecho diferencial que los distingue como únicos.

Considerar al sujeto moral como sujeto en relación con otros sujetos tiene sus raíces ya en Hegel, pero, a nuestro juicio, ha sido Lévinas quien desde un punto de vista más metafísico ha acuñado este concepto porque en él cabe decir que lo humano del hombre no consiste en su pertenencia al mundo -o en su existencia-, sino en un estar permanentemente abocado al "afuera" más exterior, a ése que le anuncia lo otro por excelencia. El otro hombre, el extraño inapropiable. La ética aparece así como filosofía primera, como anterior a la misma ontología: "La ética...es más ontológica que la ontología, un énfasis de la ontología"10. El hombre como ser en el que lo humano le confiere una entidad especial y una razón de ser lleva a cabo lo que se califica como el estallido ético de la ontología: "me pregunto si no es ésta la intuición profunda que subyace al pensamiento de Wittgenstein y que late en la afirmación de que si un hombre pudiera escribir un libro de ética que realmente fuera un libro de ética, este libro destruiría, como una explosión, todos los demás libros del mundo"11. La ética, que es lo humano, deviene así en ontología como forma de ser. La ética pasa a ser la filosofía primera, y la cuestión de la justicia, la cuestión fundamental que sustituye a la pregunta heideggeriana sobre el ser y la nada. A esto es a lo que nos referimos cuando hablamos del estallido ético de la ontología.

Esta perspectiva antropológica en la fundamentación de la ética en la que el descubrimiento y la responsabilidad de cada uno con el otro hombre se vuelven un compromiso que marca la existencia humana, podemos encontrarla también en otros filósofos como Ladrière. Para estos autores no es que el hombre se encuentre con el otro hombre y que esté obligado a pactar y a convivir con él, es que el reconocerse sujeto entre sujetos le compromete en la intersubjetividad y en la afirmación incondicional del otro. Como dice J.M. Aguirre:

El querer la vida auténtica para sí debe ser al mismo tiempo querer la vida auténtica para el otro. Este querer implica la reciprocidad. Lo que el otro es para un 'sí' este 'sí' mismo lo es para el otro, y si está llamado para la realización de sí por medio del otro, él mismo está sometido a la condición de no poder progresar hacia su propia realización más que por medio de la contribución del otro. El concepto de reciprocidad es el concepto apropiado para expresar cómo la relación con el otro especifica la dimensión ética' ${ }^{12}$.

10. Ibídem, p. 153.

11. LÉVINAS, E. Ética e infinito, o. c., p. 16.

12. AGUIRRE, J. M. "Identidad humana y antropología". En Bermejo, D. (ed.), La identidad en sociedades plurales, Anthropos, Barcelona, 2011, p. 120. 
De manera que estamos ante otra forma de fundamentar la moral, o es quizá la misma, desde otro punto de vista más intersubjetivo, porque lo que permanece es la base de que todo fundamento sigue siendo el reconocimiento del ser humano como fin en sí mismo y como ser dotado de dignidad; pero ahora cobra mayor fuerza la intersubjetividad porque, aunque la ética es algo que empieza en el propio sujeto, se encuentra con que no puede ser entendida sin el otro sujeto. La ética es intersubjetividad, la condición social del ser humano debe estar presente en nuestra búsqueda y con ella la paradoja humana que ya anunciara Ortega de libertad en la necesidad y necesidad en la libertad. La ética es relación intersubjetiva, lo cual complica aún más nuestro objetivo de fundamentarla porque ya no se trata sólo de saber cómo debo ser, sino también de cómo creo que el otro debe ser o de cómo cree el otro que debo ser yo. Ricoeur advirtió que no se había elaborado una "teoría del reconocimiento": "La noción de alteridad ocupa ahora el primer puesto de la relevancia social, y con ella, la exigencia de que los otros sean aceptados en su dignidad"13.

Pero el caldo de cultivo de la intersubjetividad es el lenguaje, la herramienta comunicativa por excelencia en la que el vínculo entre los humanos se hace visible, ya que, a fin de cuentas, como dijera Aristóteles, la palabra sirve para comunicar lo que es justo o injusto y no sólo sentimientos y emociones. Podemos definir la razón cordial como la capacidad humana que se encarga de mostrar cómo el vínculo comunicativo, que es el núcleo de la razón discursiva, no sólo tiene una dimensión argumentativa, que es lo que la ética del diálogo ha puesto de manifiesto, sino también una dimensión cordial que es la que hace posible estimar valores y compadecerse. Con ello lo que estamos infiriendo es que la verdad y la justicia se conocen también, además de por la razón argumentativa, por la razón cordial que, para Cortina, ha sido arrinconada a favor de la primera. Se alinea así nuestra autora con las teorías que consideran la inteligencia humana como una realidad compleja en la que se integran todos los afectos ${ }^{14}$.

Esto entra de lleno en la teoría más propia de Cortina que podríamos nombrar como la teoría de la cordialidad que tendría también su base en el principio de reconocimiento recíproco:

La teoría de la acción comunicativa expresa el mensaje central de la tradición del reconocimiento, al entender que en una acción comunicativa los hablantes se reconocen necesariamente como interlocutores válidos, y en ese reconocimiento básico se descubre un vínculo, la fuente de la obligación es entonces el reconocimiento recíproco de interlocutores, que se saben mutuamente imprescindibles para averiguar si una norma es justa ${ }^{15}$.

13. CORTINA, A. Ética de la Razón Cordial, o. c., p. 163.

14. En España, en los últimos tiempos, el filósofo que contribuye a exponer y divulgar esta visión de la inteligencia aplicada a la ética es J. A. Marina. Por ejemplo en sus obras Teoría de la inteligencia creadora, Anagrama, Barcelona 1993, Ética para náufragos, Anagrama, Barcelona, 1995 y La lucha por la dignidad, Anagrama Barcelona, 2000.

15. CORTINA, A. La escuela de Frankfurt, Síntesis, Madrid, p. 183. 
Hay que señalar asimismo que el reconocimiento recíproco lo encuentra Cortina muy relacionado en su origen con el sentimiento religioso, en concreto con la alianza que se establece por ejemplo en el Génesis entre Dios y su pueblo, como Cortina muestra en su obra Alianza y Contrato. Y si hemos de precisar también su fundamento filosófico, lo haremos resumiendo el reconocimiento recíproco obligado que encontramos en la razón comunicativa que nos presenta a los hombres como interlocutores válidos en busca de la verdad, la belleza o en este caso de la justicia, como seres que viven en la intersubjetividad.

Cortina da, así, con el vínculo del reconocimiento recíproco; con la intersubjetividad, como el mayor móvil de la obligación moral, de manera que el progreso ético es la ampliación de ese "otro" que dijera Lévinas o de ese "nosotros" de la ética del diálogo. La ética ha ido formando un nosotros cada vez mayor que ahora pretende ser universal. Esa universalidad encierra naturalmente grandes diferencias y desigualdades que son expresión de la heterogeneidad humana a la que no debemos renunciar. Pero hay diferencias que debemos proteger y otras que debemos subsanar, ¿cuál ha de ser el criterio?

\section{La alteridad}

Así pues, Cortina da una vuelta de tuerca a su ética mínima en la razón cordial colocando el sentimiento y la conciencia del propio valor y respeto al otro como la fuente principal de la obligación moral. Pero es que además, a esta propia dignidad, que brota ahora no sólo de la razón sino también del sentimiento, hay que unir el hecho de que los seres humanos sean dignos también por compasión. Admitir que la compasión es el principal móvil moral no es nuevo; y a pesar de ser un sentimiento que se ha ligado más a la lástima que al respeto por la dignidad de los otros, lo tenemos en Schopenhauer, en Kant, en Marcuse... y en Cortina que recuerda la última visita de Habermas a Marcuse: "¿Ves?, dijo a Habermas, ahora sé en qué se fundan nuestro juicios de valor más elementales: en la compasión, en nuestro sentimiento por el dolor de los otros. Es tal vez desde la compasión desde donde la razón humana descubre que no es miope como quieren los positivistas, que la clave de la vida social no es el individuo atomizado, sino personas que se saben vinculadas desde el origen,"16.

El ser humano se concibe pues como un sujeto entre sujetos que forman una comunidad humana. Esta comunidad se distingue de otras en que tiene la capacidad de estimar la dignidad y creemos que esto es precisamente lo genuino de Cortina de experimentar la compasión, porque como dijera A. Machado en Proverbios y Cantares (dedicado por cierto a Ortega): "Poned atención, un corazón solitario no es corazón".

Machado nos recuerda que el ojo que ves no es ojo porque tú le veas, es ojo porque te ve; el ojo mismo, como el resto del cuerpo, está hablándo-

16. CORTINA, A. "Diálogo abierto", El País, 15-5-2003. 
nos del carácter radicalmente abierto y extravertido de nuestra existencia, de nuestra apertura radical al mundo y a las personas. Por su radical apertura, el "yo" se enlaza con el "tú" y en la pluralidad unitaria del "nosotros"17.

Es entonces cuando podemos hablar también de cordialidad como alteridad porque hasta la conciencia de los derechos propios es inseparable de la de los derechos ajenos. He aquí de nuevo la apuesta de Cortina por la ética de la razón cordial que se relaciona con otras teorías (Dworkin, E. Tugendhat, Dussel) en las que se pretende abandonar el terreno de los derechos y pasar al de las responsabilidades, porque es la única manera de apostar, como dice Apel, en serio por la corrección de normas morales y por la comunidad ideal de comunicación. Y es que tomar algo en serio, es para Cortina, hacer intervenir al corazón que opta por asumir responsabilidades y no sólo por reclamar o defender derechos,

porque quien toma en serio el valor de todos los hombres concretos, se sabe-siente responsable de ellos, y de ahí que se le abra un mundo bien distinto al del derecho...: ese mundo de la solidaridad positiva... Éste es el mensaje de quienes ven en el diálogo la forma de integrar justicia y solidaridad. Pero también el mensaje de cuantas/cuantos recuerdan, frente a las éticas centradas exclusivamente en la justicia, que la conciencia de lo justo es una forma de conciencia moral, pero no la única, que en el mundo moral suena la voz de la justicia, pero también una voz diferente: la voz de la compasión y el cuidado ${ }^{18}$.

Un concepto ético clave aparece pues y es el de responsabilidad. En él se supera el sujeto con la aparición del otro y está muy ligado al de consecuencias sobre todo lejanas, como señalara Hans Jonas: "Incluye en tu elección presente, como objeto también de tu querer, la futura integridad del hombre" ${ }^{19}$. El hombre es el único ser conocido que tiene responsabilidad. Sólo los humanos pueden elegir y eso tiene consecuencias. Tenemos libertad pero por eso mismo tenemos algo

17. DíAZ, C. Persona, en Diez palabras clave en Ética, Verbo Divino, Pamplona, 2008, p. 312.

Por otra parte es curioso cómo desde perspectivas muy diferentes se trata de explicar la naturaleza humana como ligada al otro ser humano, sin el cual no se puede entender al individuo. Por ejemplo, en una interpretación tan alejada en el espacio y el tiempo como el confucionismo existe la palabra Rén, traducida como "naturaleza humana verdadera" (LIN YUTANG), "humanidad verdadera" (LEGGE), "humanidad perfecta" (P. DO-DINH), "benevolencia" (PÉREZ ARROYO), "amor al prójimo" y "bondad" (R. WILHELM). Estas traducciones aparentemente distintas tienen una explicación. El término chino está compuesto por dos palabras: "dos" y "persona". El Hombre Superior confuciano no es aquel individuo que busca realizar lo que lo diferencia de los demás, sino aquel que desarrolla su verdadero ser en la relación con el otro que aunque distinto también tiene una naturaleza común. Así por ejemplo en Analectas 4.1 de CONFUCIO, traducido por S. LEYS, tenemos el siguiente texto: "El Maestro dijo: Es hermoso vivir en medio de la humanidad. Difícilmente es sabio escoger un lugar para vivir desprovisto de humanidad".

18. CORTINA, A. Ética aplicada y democracia radical, Tecnos, Madrid, 2007, p. 155.

19. HANS, J. El principio de responsabilidad: Ensayo de una ética para la civilización tecnológica (ed. original, 1973, Herder, Barcelona, 1975), http://www.alcoberro.info/V1/jonas0.htm. 
que brota de ella: responsabilidad. La responsabilidad es la carga de la libertad. El imperativo de la responsabilidad traspasa así los límites estrechos del individuo y toma como objetivo la vida que compromete a los demás y a las generaciones futuras. También está vinculado a lo que no hemos hecho, a la omisión o a los errores históricos del pasado. Visto así, la compasión no es un gesto generoso, sino el principio moral por excelencia, porque hace nuestra la causa del otro.

Esa es la ética de la alteridad que propone Lévinas. El sujeto moral no se constituye desde la autonomía kantiana, sino desde el tú, el otro-ahí y ese es el núcleo de la responsabilidad, porque, gracias al otro nos constituimos en seres humanos. La compasión es un sentimiento moral que se construye así gracias a la razón que capta el compromiso con los otros porque el ser humano es responsable también de su realidad. La responsabilidad como concepto contemporáneo la encontramos pues como responsabilidad física de no mirar para otro lado y también como responsabilidad metafísica, porque, si el sufrimiento es injusto, todo ser humano debe luchar contra él. Estamos, pues, ante una educación moral que hace hincapié más en la ética intersubjetiva que intrasubjetiva, porque además de intentar dar razón de la moral, procura aplicarlo para orientar la acción a la vida social; y estamos también ante una educación moral en la que la felicidad se completa y se asienta sobre la justicia.

Hay por tanto que tomarse en serio la realidad y tomar en serio la realidad significa hacerse cargo de ella para ampliarla, recrearla e idear alternativas viables:

Una simple mirada a la globalidad -recuerda Ellacuría- nos muestra que existen "pueblos enteros crucificados", al menos dos tercios de la humanidad, lo cual significa que partimos ya de una situación de "des-humanidad". Un proyecto ético no puede eludir este punto de partida, sino... hacerse cargo de la realidad, cargar con ella y encargarse de ella para que sea como debe ser... Asumir estas tres obligaciones con la realidad social en la que ya estamos implantados es lo contrario de encogerse de hombros alegando que, a fin de cuentas "no soy guardián de mi hermano". Pero en este caso no sería Yahvé quien pediría responsabilidades, sino la realidad de un ingente número de seres humanos despojados de sus derechos... es preciso haber perdido mucha inteligencia para no comprender que las cosas deben ser de otro modo y que son también responsabilidad nuestra ${ }^{20}$.

Lo cual nos sumerge en la educación moral del individuo para con la sociedad y en otra consecuencia: la de educar en la responsabilidad porque somos responsables también individualmente. Estas perspectivas del altruismo, la cooperación y la solidaridad nos abren el camino de actitud humana ante los valores.

En cuanto a estos valores es conveniente señalar que la solidaridad no es para Cortina simple cooperación porque, si bien introduce la asimetría entre los que la ejercitan y los que se benefician, la cooperación, al carecer de esa relación

20. CORTINA, A. El quehacer ético, Aula XXI Santillana, Madrid, 2001, p. 88. 
asimétrica, proporciona una autoestima mucho más escuálida; y la autoestima es uno de los bienes morales primarios con los que se construye la moral.

Hay que evitar la confusión de la solidaridad con la cooperación... al menos en la medida en que se intente explicar la cooperación en virtud de agentes racionales pero egoístas, que sólo pueden llegar a cooperar cuando logran aprender por interacción repetida que la estrategia de cooperación genera mayor rendimiento que la contraria... Por tanto, no haría falta recurrir a la solidaridad para propiciar las actividades cooperadoras de los individuos ${ }^{21}$.

Hay en Cortina dos razones para apostar por la solidaridad frente a la cooperación por muy racional que ésta sea. La primera es que el reconocimiento del hombre como fin en sí mismo obliga no sólo a una cooperación que muchas veces es imposible, sino a una adhesión solidaria como actitud necesaria que considere a todos los hombres como valiosos en sí mismos y no sólo valiosos por el beneficio que pueden aportar a la colectividad.

La segunda razón es que, como el acto del habla muestra, existen dos polos: uno nos muestra a los hombres como individuos, sujetos autónomos y sería imposible el acto lingüístico sin pronombres personales; el otro nos dice que las relaciones intersubjetivas necesitan de un lenguaje que los haga capaces de reconocerse como personas. Por tanto, podemos decir que los dos principios de la ética política de Cortina son la solidaridad y la justicia.

La libertad puede existir sin igualdad y la igualdad sin libertad. La primera, aislada, ahonda las desigualdades y provoca las tiranías; la segunda, oprime a la libertad y termina por aniquilarla... A mi modo de ver la palabra central de la tríada es fraternidad. En ella se enlazan las otras dos... La fraternidad es el nexo que las comunica, la virtud que las humaniza y las armoniza. Su otro nombre es solidaridad, El único puente que puede reconciliar a estas dos hermanas enemigas -un puente hecho de brazos enlazados- es la fraternidad. Sobre esta humilde y simple evidencia podría fundarse, en los días que vienen, una nueva filosofía política ${ }^{22}$.

Aunque no sean palabras de Cortina, sino de Octavio Paz, podrían servir también para exponer la labor de bisagra por una parte y de fundamento moral por otra, que, según Cortina, tiene la solidaridad, concepto de larga historia aunque haya pasado por diferentes denominaciones como amor universal, fraternidad, reconocimiento recíproco, etc.

21. CONILL, J. "Ética universal de la cooperación y el desarrollo solidario". En Jongitud, J. Ética del desarrollo y responsabilidad social en el contexto global, Universidad Veracruzana, México 2007. http://www.etnor.org/doc/Conill-Desarrollo-2007.

22. PAZ, O. La otra voz. Poesía y fin de siglo, Seix Barral, Barcelona 1990, p. 129. 
El nuevo sujeto moral está inmerso también podríamos decir en la fraternidad. Pero la fraternidad no es solo un valor sentimental, debe entrar en el terreno de los hechos. Es una exigencia que como la de la familia se nos impone, no así la amistad, por ejemplo, a la que se invita pero que no puede imponerse. La fraternidad no es un acto libre de la voluntad, es lo que nos induce a reconocernos en algo que nos sobrepasa y que nos forja en nuestra identidad. La fraternidad está presente, pues, mucho antes de que lo proclamara la Revolución Francesa secularizada del cristianismo. Fuera de toda referencia religiosa la fraternidad sería una realidad universal fundada sobre la constancia de que todos los hombres viven juntos en una suerte de comunidad de destino... un compromiso para respetar al otro en sus derechos y sus necesidades en su singularidad. La fraternidad aspira a liberar a los hombres de todo lo que les opone y les pone en conflicto... La fraternidad aparece así como un vínculo más obligado que voluntario. En este mismo sentido, por buscar voces diferentes, reflexiona sobre la interpelación del mendigo, por ejemplo, A. Arteta en su reciente libro:

¿Alguien negará que ese cara a cara de su solicitud desasosiega?... Hay un vínculo muy profundo que enlaza el sentimiento de culpa con la mirada del otro que nos pide socorro económico... ¿ ¿Seguiré diciendo que con mi dinero puedo hacer lo que me da la gana o hay algo que siempre debo hacer con él? ${ }^{23}$.

\section{La ley natural}

Otro problema se nos puede plantear acerca de la razón cordial o de la cordialidad: ¿Hemos de considerarla fruto de una bondad natural o es más bien algo que hay que instalar en los humanos porque, por naturaleza, la única ley que está instalada es la ley de la selva?

H. Arendt estableció una teoría alternativa a la perversidad o bondad de la naturaleza humana: la banalidad. El mal no puede ser radical y banal a la vez. Los actos humanos en la mayoría de los casos incluso en los más execrables como los practicados por A. Eichmann en la masacre de los judíos son, lamentablemente, banales, irreflexivos mecánicos y en realidad fruto del obligado cumplimiento de unas órdenes. Eso hace que el mal sea más difícil de combatir porque en los humanos viene disfrazado o envuelto en costumbres, hábitos, formas de vivir, prejuicios, órdenes...

En esta línea, A. Cortina recuerda la lección de aquel indígena que explicaba a los niños que en las personas hay dos lobos, el de la maldad y el de la bondad. Uno de los niños le preguntó ¿cuál de los lobos crees que ganará? El que alimentéis, le respondió. En efecto, superadas ya las tesis de que la naturaleza humana es malvada, tesis a veces mantenidas por las grandes religiones y a veces por

23. ARTETA, A. Si todos lo dicen, Ariel, Barcelona, 2013, p. 81. 
teorías como las de Hobbes, surge la moral como un complemento imprescindible en el ser humano que pone freno y conduce el comportamiento por caminos que nos separan de la perversidad con la que la naturaleza nos ha "obsequiado".

Las teorías de Darwin y de sus seguidores sobre la evolución de las especies han servido, sobre todo en el darwinismo social, para justificar desde el neoliberalismo más feroz hasta la eliminación de personas consideradas débiles o simplemente inferiores. Si la competencia es la expresión de la vida, ¿por qué ponerle freno? Interpretar el darwinismo de esta forma tan simple es seguramente un error, sobre todo porque aunque el ser humano está sometido también a la ley de la supervivencia y de la selección natural, su diferencia con los animales es más de grado que de naturaleza: los rudimentos de la moral están presentes también en los animales como demuestran algunos trabajos realizados con primates, en los que se da cuenta de comportamientos cooperativos y compasivos. Pero no bastan estos rudimentos para superar el egoísmo y en último término fundamentar la moral:

La naturaleza no nos obliga a pelear todos contra todos, pero tampoco a mostrar una buena voluntad sistemática. El buen salvaje es tan imaginario como el salvaje malo. Los dos tipos de comportamiento tienen su origen en nuestra naturaleza animal, pero el predominio de uno u otro depende de las circunstancias ${ }^{24}$.

En apoyo de esta moral natural que nos inclina al altruismo están los modernos estudios de neurología y, en concreto, los descubrimientos de las neuronas espejo. V. Ramachandran ${ }^{25}$ afirma, por ejemplo, que estas neuronas conformaron la civilización. Son las responsables de que seamos capaces de imitar a los demás y lo que es más importante, de que nos pongamos en el lugar del otro y que ese otro aparezca ante nosotros como el alter ego, sin el cual es imposible entender al ser humano. Diríamos entonces que los hallazgos de la neurociencia con las neuronas de la empatía avalan las teorías como la de Lévinas que sitúan al otro hombre como el reciprocante que dice Ortega:

La realidad que este nombre (hombre) representa sólo me aparece cuando hay otro ser que me representa o me reciproca. Muy bien lo dice Husserl: El sentido del término hombre implica una existencia recíproca de uno para el otro, por tanto una comunidad de hombres, una sociedad. Y viceversa, es igualmente claro que los hombres no pueden aprehenderse sino hallando otros hombres en torno a ellos...el hombre aparece en la socialidad como el Otro, alternando con el Uno, como el reciprocante ${ }^{26}$.

24. TODOROV, T. “¿Solidaridad natural?”, El País, 14-8-2012.

25. RAMACHANDRAN, V. Lo que el cerebro nos dice, Paidós, Barcelona, 2012. En una línea similar están apareciendo obras como la de CHURCHLAND, P. El cerebro moral, Paidós, Barcelona, 2012.

26. ORTEGA Y GASSET, J. El hombre y la gente, Obras Completas, Volumen VII, Alianza Editorial-Revista de Occidente, Madrid, 1983, p. 148. 
Así es como se forma el nuevo sujeto moral que integra la ética cordial, un sujeto que coloca las emociones en el lugar en el que tienen que estar en la ética o sea en el corazón y no solo en la cabeza ${ }^{27}$, por eso necesitamos un magisterio ético que nos ayude a gobernar las emociones.

Desplazada un tanto la vieja polémica alma-cuerpo, mente-cerebro, el conflicto de Frankenstein aparece de nuevo:

Ese era en realidad el mensaje de Mary Shelley: que los miembros y los órganos de un ser humano, incluido el cerebro, pueden ser muy perfectos, pluscuamperfectos, pero nada garantiza que su vida sea una vida buena si no puede contar con otros entre los que saberse reconocido y estimado... ${ }^{28}$.

Cortina toma así las neurociencias con cautela porque es al final la individualidad humana, el reconocimiento recíproco lo que hay que salvar antes que la bondad o maldad de los actos. Vemos aquí aparecer el homo reciprocans como el fundamento del homo ético. Por eso, para Cortina, el homo oeconomicus ha dado paso al homo reciprocans, hombre en el que también hay en principio más interés que altruismo porque espera que los demás correspondan, devuelvan lo recibido o, como poco, tengan la predisposición a cooperar.

Conviene, pues, desempolvar la antigua tradición del contractualismo y construir una teoría de la justicia, alternativa al utilitarismo y al perfeccionismo, sobre la base del pacto social... las conductas altruistas no se explican con el hombre económico, pero tampoco con el altruismo genético... es preciso contar con la realidad de un hombre capaz de reciprocar, un hombre reciprocador, que es la base del pacto social, y además en el sentido de la reciprocidad fuerte... una versión darwinista del imperativo categórico que dice así: obra sólo de tal modo, que si los demás obraran como tú, se maximizaría la capacidad adaptativa ${ }^{29}$.

En aras precisamente de la interdisciplinariedad y de la neuroética no estaría de más hacerse eco de este evolucionismo crítico que partiendo de S. Gould se mantiene hoy día como una alternativa a la teoría por excelencia de la biología actual: al evolucionismo darwiniano,

al dogma intocable de la Biología: porque la Naturaleza, la vida, no tiene nada que ver con la sórdida concepción competitiva, individualista, egoísta que nos han transmitido... La imposición de la interpretación patológica de la Naturaleza, de una vida regida por el egoísmo y la competencia y en la que el éxito es para los más aptos ha llevado a que las sociedades se hayan convertido en un inhóspito campo de batalla en el

27. CAMPS, V. El gobierno de las emociones, Herder, 2012.

28. CORTINA, A. "Frankenstein: el origen de la Neuroética", El País, 17-10-2010.

29. CORTINA, A. Neuroética y neuropolítica, Tecnos, Madrid, 2011, pp. 120-121. 
que el individualismo, la competencia, y la soledad son las que rigen las relaciones humanas ${ }^{30}$.

Y es que para algunos autores muy críticos y beligerantes con el paradigma científico dominante del darwinismo, nada es gratuito ni inocente, y en este sentido la biología evolucionista al uso ha servido para justificar un tipo de economía y un tipo de sociedad. Podríamos decir quizá que ha impuesto una moral dominante que asume el individualismo, la supervivencia de los más aptos y la lucha por la supervivencia como la mejor forma, ya inscrita en la naturaleza, de vivir. La ciencia no es una actividad autónoma y aislada, sino una actividad que se integra en una sociedad y en su funcionamiento.

La no intervención del Estado en la economía, el laissez faire ¿no podrían rememorar el principio del azar en la evolución? ¿Y qué decir de la coronación del egoísmo del gen?... Para Adam Smith, era el egoísmo del carnicero... el que hacía a la sociedad funcionar; para Richard Dawkins, es el egoísmo del gen el que hace a la naturaleza funcionar... si creemos en una nueva sociedad necesitamos creer también en una nueva ciencia ${ }^{31}$.

Desde otro punto vista, Mauricio Abdalla, por ejemplo, llega a parecidas conclusiones, porque según él, el error del individualismo viene de antiguo, exactamente de la concepción del individuo como el principio constituyente elemental de la sociedad cuando en

la esencia de lo que se considera humano está el lenguaje, el trabajo, las costumbres, la cultura, etc., y esto sólo se adquiere en la vida en sociedad. Aislado del medio social el ser humano no se humaniza... Por tanto, un conjunto de individuos "no humanizados" no forma una sociedad... Por consiguiente, la sociabilidad se impone, por un criterio lógico, como anterior y determinante del individuo humano, aunque históricamente no se pueda tener tampoco una sociedad sin individuos ${ }^{32}$.

Pues bien, para Abdalla es esta visión individualista de la sociedad la que fundamenta la creencia en que la economía, los mercados y los valores financieros son incontrolables, cuando en realidad podemos hablar de una prioridad lógica de la sociedad sobre el individuo porque le precede a pesar de que no podamos concebirla sin la existencia de él. El ser humano real tiene sin embargo así otra prioridad, pero ontológica, sobre la sociedad. Por ello el eje fundamentador de una nueva racionalidad no es el interés individualista sino el principio de cooperación que está en clara contradicción con el trueque competitivo, por eso este principio

30. SANDÍN, M. Pensando la evolución, pensando la vida. La biología más allá del darwinismo, Cauac Editorial Nativa, Sevilla, 2010, pp. 13-19.

31. ABDALLA, M., en SANDÍN, M. Pensando la evolución, pensando la vida. La biología más allá del darwinismo, o. c. Prólogo a la primera edición.

32. ABDALLA, M. El principio de cooperación, Ediciones Crimentales, Murcia, 2007, pp. 84 y ss. 
es una afirmación necesariamente revolucionaria. No podemos concebirlo como una adecuación al orden predominante, sino como praxis destructora del eje fundamentador de la economía capitalista y de todas las relaciones sociales sometidas a la racionalidad del mercado. Es a partir de ese eje que se edificarán las demás formas de relación humana, nuestras construcciones teóricas, nuestra ontología, nuestra ética, nuestro humanismo, nuestra visión sobre el universo y nuestra acción sobre la naturaleza ${ }^{33}$.

Puede que estemos asistiendo, así, al nacimiento de un nuevo paradigma explicativo de la evolución humana que tendría un gran sentido para la ética porque toma el interés de la cooperación y del altruismo como el instinto básico de supervivencia frente al tan exitoso gen egoísta de Dowkins. Es decir, quizá haya que admitir al menos tanto un gen egoísta como un gen altruista que sería el responsable de una especie de bondad natural o de una empatía que nos transforma en seres bondadosos.

Cayó en mis manos el recién publicado libro "The age of Empathy" (La época de la empatía) del primatólogo Frans de Waal, cuya tesis es: "basta ya de creer que somos egoístas por naturaleza. ¡No lo somos! Las investigaciones en conducta animal llevan años sugiriendo que debemos cambiar este paradigma, y asumir que la evolución ha insertado la empatía y la solidaridad en nuestro comportamiento básico ${ }^{34}$.

Quizá con el evolucionismo estamos ante un pretendido pensamiento único y aunque Darwin insistiera en que su teoría sólo pretendía ser una explicación de la variedad de especies existentes, lo cierto es que se ha instalado como ley natural el hecho de que la injusticia esté inscrita en la naturaleza y que el altruismo o la cooperación sea, no ya la excepción, sino la anti norma de la naturaleza.

Necesitaríamos entonces, para salvar al hombre de este determinismo biológico, que el paradigma explicativo de la evolución entrara en crisis como Khun propone y fuera sustituido por un nuevo paradigma científico que elimine esta concepción de la vida como algo patológico y esencialmente competitivo.

No es cuestión de que el sujeto moral esté fundado en una antropología o una moral neoempirista que posibilitaría un nuevo humanismo fundamentado en la naturaleza humana, sino de aceptar que la naturaleza humana es tan compleja que en ella coexisten instintos de signo contrario ${ }^{35}$. Hobbes y Rousseau habrían descrito la naturaleza humana pero de forma incompleta pues habrían descubierto sólo una de

33. ABDALLA, M. o. c., p. 105.

34. ESTUPINYÁ, P. El ladrón de cerebros, Mondadori, Barcelona, 2010, p. 408.

35. PINKER, S. Los ángeles que llevamos dentro. El declive de la violencia y sus implicaciones. Paidós, Barcelona, 2012. La tesis central de éste último libro de Steven Pinker es que la época en que vivimos es la menos violenta y cruel de cuantas ha habido a lo largo de la historia, lo cual iría también en la línea del progreso moral de Habermas. Otra visión reciente es la de S. Giner que en su también reciente libro El origen de la moral cuestiona ese supuesto 
sus caras. Será luego nuestra razón y nuestra capacidad de organizar la convivencia la que haga desarrollar una u otra. No somos lobos para los demás pero tampoco corderos. Algo que coincide ya más con la teoría kantiana de la "insociable sociabilidad" del ser humano. De cualquier manera hemos de tener en cuenta que la ética queda al margen de estas leyes inscritas en la naturaleza, porque, para empezar, que una cosa sea así no significa que deba ser así.

\section{La creatividad}

La razón cordial viene pues definida por los valores del reconocimiento del ser humano como un fin en sí mismo, lo que nos lleva, como hemos visto, al reconocimiento del otro, a la alteridad, al altruismo, a la compasión, a la solidaridad, pero qué hacer cuando esos valores no prenden en la acción humana, o lo que es lo mismo ¿cómo hacer que lo que vale la pena se imponga?, el deber moral debe imponerse a la ganancia individual, pero ¿cómo ha de hacerse?, ¿cómo garantizar que eso ocurra? Recordemos a este respecto que el subtítulo de la Ética de la razón cordial es educar en la ciudadanía del siglo XXI, lo que nos traslada, según A. Cortina, al ámbito de la educación como un factor determinante en la formación del carácter.

Recientemente Goleman con su inteligencia emocional ${ }^{36}$ ha remitido a una tradición filosófica según la cual el ser humano es un ser afectivo además de inteligente. En esta línea se sitúa Cortina cuando dice: "Si alguien adoleciera de ceguera emocional, no tendría interés en nada ni podría preferir entre distintas alternativas, aunque tuviera un altísimo coeficiente intelectual" 37 . Esta concepción, que integra los sentimientos dentro de la inteligencia y dentro por tanto de la creación ética, nos lleva en la educación moral a la imprescindible educación de los sentimientos en la pretendida educación del carácter. La etimología de educar es educare, que tiene por raíz ducere, o sea, conducir. La RAE define educar como desarrollar o perfeccionar las facultades intelectuales y morales de una persona por medio de preceptos, ejercicios, ejemplos, etc. Este desarrollo implica, pues, una meta previamente propuesta, lo que hace pensar en que es imprescindible el esfuerzo y los proyectos a largo plazo.

En una razón cordial en la que el corazón juega tan gran papel según hemos venido diciendo, la educación emocional es tan importante como la educación en los conocimientos. Una persona moralmente educada es la que controla su vida y pone sus conocimientos y sus sentimientos al servicio de ella, porque no es el éxito social lo que busca la educación moral, sino el éxito moral. Cortina señala que por suerte o por desgracia,

progreso moral. GINER, S. El origen de la moral. Ética y valores en la sociedad actual, Península, Barcelona, 2012.

36. GOLEMAN, D. Inteligencia emocional, Kairós, Barcelona, 1996.

37. CORTINA, A. Ética de la Razón Cordial, o. c. p. 248. 
las cosas no son tan sencillas, porque la educación del deseo encierra siempre un doble lado, el de lo útil y el de lo valioso por sí mismo, el de lo deseable por el beneficio que reporta y el de lo deseable como digno de ser deseado, el del cálculo que se expresa en el lenguaje de los recursos, y en el de lo admirable, por eso la educación del deseo es también como un proceso de degustación de aquello que merece la pena por sí mismo, como la libertad o la equidad, como un proceso de degustación de una vida digna de ser vivida en la que tiene un lugar indiscutible la cordura, la sabiduría cordial ${ }^{38}$.

Es decir, la prudencia, el juicio, la sensatez, son ingredientes de la sabiduría moral. En este sentido, Cortina propone tres ejes sobre los que la educación debe articularse: el primero es el conocimiento, el segundo, la prudencia; el tercero, la sabiduría moral.

Zubiri con su inteligencia sentiente, Unamuno, Tocqueville son también buenos antecedentes de esta razón cordial que Cortina reivindica como la constructora de la ética universal: No está sola, pues, Cortina en esta perspectiva de la moralidad que pretende si no crear, sí recuperar el terreno de los afectos en el comportamiento humano y en concreto la importancia de tener en cuenta a los otros humanos en ello. Desde los estoicos, Kant, Hegel, la ética dialógica, Lévinas, Dussel, hasta la ética de la liberación más actual podemos encontrar referencias a estos mismos planteamientos. Es más, si abrimos nuestra mirada a esta perspectiva de la responsabilidad compartida con los otros que se articula desde el corazón, desde la humanidad, observamos un clamor en esferas tan distintas del mundo intelectual como son los del mundo laboral, político, social o económico:

La ética, para ganar un mínimo de consenso, debe brotar de la base común y última de la existencia humana. Esta base no reside en la razón, como siempre ha pretendido Occidente. La razón "y esto la misma filosofía lo reconoce" no es ni el primero ni el último momento de la existencia. Por eso no explica todo ni abarca todo... Por lo tanto, la experiencia de base no es "pienso, luego existo", sino "siento, luego existo". En la raíz de todo no está la razón ("logos"), sino la pasión ("pathos"), que se expresa por la sensibilidad y por el afecto. Para este tipo de razón captamos el carácter precioso de los seres humanos, lo que los hace dignos de ser deseables. Desde el corazón y no desde la cabeza, vivenciamos los valores. Por los valores nos movemos y somos ${ }^{39}$.

Se abunda pues, en este sentido, en establecer un tipo de vínculo con los otros humanos que radica no tanto en un pacto como interpretan los pensadores contractualistas sino más bien en una "alianza", en un compromiso que no podemos deshacer sin deshumanizarnos, como, por ejemplo se señala en La Biblia cuando se habla

38. Ibídem, 252.

39. BOFF, L. "Ética a partir del calentamiento global", http://www.servicioskoinonia.org/ boff/ artículo. 
de la alianza entre Dios y su pueblo. Un compromiso que además de ser aceptado es querido porque está grabado también en la voluntad humana: "Pondré mi Ley en su interior y sobre sus corazones escribiré" (Jeremías, 31, 33) ${ }^{40}$.

Valer y ser son las dos dimensiones de las cosas que los humanos apreciamos. "Los valores son valiosos y por eso nos atraen". Los valores no son ángeles abstractos, sino que están incorporados a la vida humana Podríamos decir, además, que los valores tienen en la comunidad humana su lugar natural. Los valores, que son los elementos con los que se construye la moral, no pertenecen a la categoría del ser de las cosas, sino a una dimensión especial que les hace ser creación humana en tanto que hay que apreciarlos, quererlos y degustarlos. La capacidad de realizar esto es universal; de ahí la importancia de la educación y de la cultura que los transmite. Para Cortina, es la razón la que teje una urdimbre con los proyectos del corazón y así aparece la razón cordial en la que "junto al espíritu geométrico, late el espíritu de la finura que nos hace conocer de otra forma"'41.

Esta cuestión es importante porque, si inventamos los valores, estamos abocados al relativismo moral y será más complicado defender unos valores frente a otros. Si, por el contrario, los valores los reconocemos, ¿por qué no podemos estimarlos de forma universal? La solución para Cortina en este asunto está en un punto intermedio: los reconocemos, los captamos, pero en ello nuestra capacidad creadora tiene algo que decir, no son pura creación subjetiva. El valor se refiere a la cualidad de las cosas. Machado decía que "es de necios confundir valor y precio". Es exacto. Los precios los ponemos nosotros, son convencionales, relacionales, pero no subjetivos o relativos; los valores ya vienen dados porque son cualidades reales que según Cortina descubrimos creativamente.

Dado que el hombre tiene una necesidad imperiosa de hacerse con la realidad, como todo ser vivo, y que los instintos no dirigen su comportamiento como en los animales, esa libertad, esa anuencia como diría Ortega, le arroja a un escenario pero sin papeles: tiene que inventarlo todo y lo hace con la herramienta que posee: la inteligencia.

Decía Hölderlin que "poéticamente habita el hombre la tierra"; creadoramente, haciéndose, "poiein". El animal vive, el hombre super-vive; o sea, vive por encima de sus realidades porque tiene muchas posibilidades, muchos posibles. Esta creatividad de la que hablamos en el descubrimiento de los valores, confiere un dinamismo que es necesario comentar, porque es el motor de la ética, lo que le hace ser una disciplina práctica, progresiva y realmente humana. Los valores son positivos o negativos y, en consecuencia, atraen o repelen; no dejan indiferentes, no son neutrales. Diríamos que nos interesan siempre, no podemos permanecer ajenos a ellos. Por ello, más vale, según Cortina, reconocerlos en

40. Cortina explica esta diferencia en su libro Alianza y Contrato, Trotta, Madrid, 2010.

41. CORTINA, A. Ética de la Razón Cordial, o. c., p. 127. 
voz alta, ya se trate de valores políticos, económicos, educativos o de cualquier otra índole. Pero es más, si admitimos, como lo hacemos, que los valores son dinámicos y nos mueven a actuar en una dirección, es necesario admitir que también hay una lógica de los valores que nos obliga a seguir los positivos y rechazar los negativos:

Por eso podemos decir que la creatividad humana forma parte del dinamismo de la realidad, porque actúa como una partera que saca a la luz lo que ya estaba latente, alumbrando de este modo nuevos valores o nuevas formas de percibirlos. Los grandes genios y los grandes creadores de la humanidad son piezas indispensables de este dinamismo de la realidad, pero también los ciudadanos de a pie en la medida en que todos y cada uno son capaces de alumbrar nuevas perspectivas de valor ${ }^{42}$.

La educación moral no debe quedar reducida a la obediencia de normas, porque, para que una sociedad sea justa, no bastan las normas jurídicas que siempre obedecen a razones estratégicas. Es necesario algo más. Para Cortina, es necesario interiorizar las normas y degustar los valores. Recordemos a este respecto a los animales de la isla del doctor Moreau con los que Cortina ilustra su teoría. Pero, aunque ya está muy utilizado, para nosotros más clásico e ilustrativo de este necesario sentimiento moral es "el anillo de Giges" platónico; de cualquier manera, en ambos aparece el ingrediente imprescindible de la ética que es la aceptación y no la imposición de las normas, cosa que se acerca más a la tradición kantiana y dialógica de la ética. Se trata, por tanto, en la educación moral, según Cortina, de interiorizar un criterio moral para apropiarse de valores o virtudes como decía Aristóteles, con los que hacer frente a la vida y hacerse cargo de la realidad. Con ello nos acercaríamos así a comparar una sociedad moralmente educada con una sociedad sana en el amplio sentido de la palabra, aquella en la que los individuos se autoposeen y son capaces de controlarse a sí mismos.

La educación es el pilar fundamental de la formación de la sociedad civil, y en este caso podemos relacionar claramente la posición de Cortina con la de J. A. Marina, cuando éste utiliza el dicho africano de que para educar a un niño hace falta la tribu entera porque, para inculcar la idea de sociedad y de persona que queremos, no educa sólo la escuela, educa la sociedad entera. Somos seres individuales que se sostienen gracias a los otros seres individuales con los que tenemos que convivir, aprender a hacerlo es aprender a vivir, porque nosotros no vivimos, convivimos y si no salvamos nuestra circunstancia, no nos salvamos a nosotros, como Ortega sentenciara. Necesitamos que la sociedad avance hacia la dignidad y hacia el progreso social y moral que se manifiesta en la consecución de derechos. La educación tiene en este asunto una gran importancia y su objetivo no puede ser sólo el de obtener ingenieros, por ejemplo, sino el de hacer buenas personas al más puro estilo platónico. La educación actúa contra ciertas

42. Ibídem, 144. 
predisposiciones. Debemos escoger las buenas y evitar las malas. De nuestra escuela dependerá cada vez más el progreso social, económico y ético del país. La consecuencia mayor de la educación moral, que brota también de la condición social del ser humano, es la de la educación cívica, no sólo porque ha de hacerse cargo de su realidad, sino porque

la educación empieza por sentirse miembro de comunidades: familiar, religiosa, étnica. Pero también miembro de una comunidad política, en la que el niño ha de sentirse acogido desde el comienzo... Para formar hombres es, pues, necesario formar también ciudadanos ${ }^{43}$.

Y es que, por ejemplo,la compasión ante el dolor ajeno, la indignación frente a la injusticia, el respeto ante la dignidad humana son tres sentimientos fundamentales que se deben fomentar en la escuela. Eso sería para Cortina ser responsable de la realidad que al hombre le toca vivir.

¿Qué hay de nuevo, pues, en la ética de la razón cordial de Cortina con respecto a la educación?: la necesidad de fundamentar la ética en la capacidad para apreciar los valores, o si se quiere, la capacidad para apreciar lo bueno y lo justo; y en consecuencia, la necesidad de abandonar el analfabetismo moral. E igual que el analfabetismo es imposible de eliminar sin un esfuerzo y un cultivo continuo, sin una estrategia y un plan de formación, el analfabetismo moral se logra abandonar sólo con la formación del carácter que predispone a buscar la verdad o la justicia. Y así, por ejemplo, quien quiera imponer y hacer valer sólo su norma, sin ponerla en cuestión, no saldrá nunca del analfabetismo moral. De ahí la importancia de la educación moral para combatirlo.

\section{La ciudadanía}

La configuración de una ética cívica tiene lugar en España porque al hilo de la transición política se da una teoría ética en los años 70 del siglo pasado. Los modelos de vida buena, el utilitarista y el aristotélico, dan paso a los modelos de vida justa. Podríamos decir que la reflexión sobre qué es la vida feliz da paso a una reflexión prioritaria como es intentar una sociedad justa sin la cual es imposible la felicidad. Sigue, pues, en esto también Cortina la estela de Aranguren para quien, por una parte, la moralidad ha de integrarse en las instituciones político-sociales y, por otra, la ética debe intervenir en la política en cuanto que ésta persigue la justicia y también la felicidad de los individuos.

La perspectiva de Cortina es que la historia humana es también la conquista de una justicia que antes era terreno de beneficencia o si se quiere de paternalismo. Kohlberg propone la evolución de la conciencia moral de la sociedad y Habermas se suma a ella, Cortina interpreta esta evolución como un proceso en

43. CORTINA, A. El quehacer ético, o. c., pp. 106 y 107. 
la idea de justicia en el que se han ido reconociendo derechos que antes eran patrimonio de la beneficencia. Bien es verdad que este progreso no debe ser ilimitado pues hay necesidades humanas que no pueden ser exigibles como razones de justicia, la necesidad de amor, por ejemplo. A su vez, el hecho de que haya cuestiones que no caen en el terreno de la justicia no significa que se opte por "una razón perezosa", sino por una razón diligente, que amplía el ámbito de lo posible. Se trata, en suma, de hacer real lo posible. Y precisamente la política no es el reino de la moral sino el reino de lo posible; en ella lo utópico es sustituido por la realidad social que cambia constantemente.

La justicia aparece entonces como el impulso vital, el élan vital bergsoniano, el eje vertebrador de la ética, porque la sabiduría práctica se encamina hacia ella como su lugar natural, al igual que el conocimiento se dirige a la verdad o la estética a la belleza misma. La tríada platónica conserva la verdad y la belleza, pero la bondad pasa a ser ahora cosa de invitación, porque es a la justicia a la que le corresponde aquello que se puede universalizar racionalmente. La búsqueda de los rasgos comunes que coinciden en las sociedades que tenemos por justas cuenta con la cara de la ética filosófica, pero también con la de la ética práctica, que en este caso es la ética de los ciudadanos, la ética cívica, cuyo fundamento no es otro que la ética comunicativa y cuyo móvil es la razón cordial. Razón cordial que Cortina toma de Ortega porque es "el quicio y la vital eficacia de toda actividad humana como la moral, la política, la economía o el derecho ${ }^{\prime \prime 4}$.

Y es que ser ciudadano es, por definición, convivir con otros de los que se depende para la construcción de una comunidad:

No existe la independencia que ha sido el santo y seña de las teorías atomistas, sino la interdependencia de los iguales... las virtudes del ciudadano son el afán de autonomía y la conciencia de interdependencia a la que venimos llamando compasión... tal vez debiéramos entender la justicia como esa virtud-marco que articula cuidadosamente la autonomía, la siempre deseable capacidad de hacer la propia vida, y la compasión, la conciencia de hacerla con otros, con aquellos a los que se reconoce como iguales, como aquellos de los que se depende en la tristeza, pero también en el gozo ${ }^{45}$.

La sociedad civil lleva unido un concepto que le da contenido, se trata del concepto de ciudadanía. En efecto, la sociedad civil está compuesta por seres humanos, personas que se distinguen por ser ciudadanos. El concepto de ciudadanía es para Cortina uno de esos conceptos que engloba todas las referencias de la justicia. Si, en efecto, la justicia es la primera cara de la moneda de la ética, y es también el objetivo de la política buena, de la economía buena y el concepto que define el derecho, la formación de buenos ciudadanos es la gran apuesta del futuro. Nada más parecido al ideal platónico de la filosofía y también al de

44. CORTINA, A. Justicia cordial, editorial Trotta, Madrid, 2010, p. 13.

45. Ibídem, 62-63. 
Hegel, en los que ser un ciudadano bueno era ser un ciudadano justo en una ciudadanía o Estado justo.

Por eso ve Cortina en esta ética cívica una forma de revitalizar la ética aplicada a la vida social. Porque, a fin de cuentas, es en la sociedad civil donde se materializan los principios éticos de la autonomía, la responsabilidad, la intersubjetividad, la solidaridad... Por eso, para Cortina, el Estado debe empezar a no arrogarse lo que no es, y no investirse en otra cosa que en garante y facilitador de la moral cívica. Cortina aboga así por una sociedad civil cargada de moralidad en la que los principios del liberalismo: individuo, derecho y contrato, se vean superados por los mínimos de derecho y justicia. Y decimos sociedad civil y no Estado, porque éste se ha revelado ya insuficiente para lograr ese mínimo con el que muchos nos conformaríamos de momento. No es pues un Estado legislador quien construye un mundo ético.

Esta es otra de las consecuencias que podemos extraer: que estamos hablando en este discurso de una comunidad que no se identifica con el Estado, sino más bien con la sociedad civil, que es como un mosaico con un núcleo de valores compartidos: el compromiso con la democracia, el respeto a la diferencia, la disposición al diálogo... Una sociedad civil que, en la medida que mantiene este vínculo común de valores, es también universalista aunque su forma de actuación sea concreta, puntual y cercana. Es más, son ellos, los ciudadanos de las sociedades concretas, los transmisores de los valores morales.

Responsabilizarse de las comunidades concretas es importante, no porque defiendan unos valores que nadie más defiende, cosa a todas luces falsa, sino porque el compromiso con lo local es indispensable para realizar también lo universal. Desentenderse de lo próximo, de la comunidad de pertenencia, no es la mejor manera de ir construyendo una réplica de toda la humanidad, sino todo lo contrario; pero, a la vez, el horizonte moral de las comunidades políticas concretas no puede ser sino el de una humanidad en su conjunto ${ }^{46}$.

Una democracia a la altura de los tiempos debe procurar para Cortina algunas transformaciones que merecerá la pena por lo menos mencionarlas aquí: el concepto tradicional de bien común debe, si no cambiarse, sí al menos concretarse en la exigencia de unos mínimos éticos; la democracia sustancial, en la procedimental, lo legítimo, en lo justo; lo políticamente correcto, en lo éticamente correcto; las normas comunitarias, en los principios universalistas, el individuo propietario, en el autónomo solidario. Porque la necesidad de la globalización de la ética no le viene sólo de las pretensiones de validez universal que siempre ha tenido y que son parte de su esencia, sino también de la obligación que tenemos, hoy sobre todo, de globalizar la normatividad y la justicia.

46. CORTINA, A. Alianza y contrato, Trotta, Madrid, 2001, p. 85. 
Según Cortina, dos son los caminos de esperanza que se abren en la política en sentido amplio en un mundo globalizado como el nuestro. En primer lugar, el de las comunidades internacionales que consiguen intervenir en las políticas transnacionales, como la ONU o la UE; y en segundo, las organizaciones cívicas de ciudadanos que actúan localmente con un pensamiento global. En este sentido, Cortina atiende especialmente a la empresa y a la economía cuyo objetivo no debería ser otro que el de crear una buena sociedad mundial: "Conjugar los esfuerzo de instituciones políticas, organizaciones solidarias y empresas éticas es la clave para una justicia mundial" ${ }^{\prime \prime 7}$. Decidir qué es lo irrenunciable en un mundo tan globalizado, es muy complicado. La propuesta de Rawls, o la de M. Walter del Parlamento de las Religiones Mundiales son propuestas a las que habría que añadir otra: la de la ética de la razón cordial, que pone su acento en la ética cívica y en el protagonismo de los ciudadanos, que conoce la justicia no sólo por la razón sino también por el corazón y cuya base es el reconocimiento recíproco. Para Apel, por ejemplo, es éste el gran reto de la ética:

La globalización hasta ahora caracterizada sólo debería considerarse como un fenómeno de globalización de primer orden. Es un desafío para la reflexión filosófica y en consecuencia, para una movilización de la responsabilidad moral para la creación de un nuevo orden de interacción humana que podría llamarse un proceso de globalización de segundo orden...la necesidad de una ética universal en nuestros tiempos ${ }^{48}$.

\section{La valoración}

La autonomía del ser humano o la capacidad de darse a sí mismo las normas morales desde la racionalidad, el diálogo y la cordialidad es el principio general sobre el que Adela Cortina construye toda la teoría ética. Pero, aún siendo el punto de partida claramente kantiano, sus aportaciones ensanchan este propio planteamiento y también el panorama que presenta la tradición ética española, sobre todo la línea marcada por J. L. López Aranguren. Cortina ha ido perfilando su postura en la autoconstrucción del ser humano a través de una disciplina constante en la que la educación es la mejor herramienta de superación.

Con todo, donde Cortina muestra su lado más informal y más antropológico éticamente hablando, es en la propuesta de una Ética Cordial que complete y termine fundamentando tanto una Ética Mínima como una Ética Dialógica. Lo que Cortina descubre es que finalmente la razón no tiene la capacidad suficiente para convencernos de que obremos moralmente. Por eso la educación sentimental y la educación del corazón son imprescindibles para generar valores como la compasión o la

47. CORTINA, A. Justicia cordial, o. c., p. 143.

48. APEL, K.O. Globalización y necesidad de una ética universal. El problema a la luz de una concepción trascendental y procedimental de la ética discursiva, en CORTINA, A., Razón pública y éticas aplicadas, Tecnos, Madrid, 2003, p. 192. 
indignación ante la injusticia. Cortina rompe con ello el abismo que tradicionalmente existe entre razón y emoción porque la razón formal, universal y dialogante necesita calar en los individuos si quiere ser eficaz y esto sólo se consigue actuando sobre la motivación, sobre las emociones, sobre lo que nos mueve a actuar.

La gran contribución de Cortina está aquí, en la introducción de una categoría nueva que da posibilidad al reconocimiento de los valores éticos. Se trata de la cordialidad, porque aunque el hecho de que algo valga en sí es ya el comienzo de la moralidad, Cortina presenta la versión cálida de la ética del discurso al hacerse cargo no sólo de los argumentos, sino también de otros aspectos como los afectivos, la libertad, la igualdad, la solidaridad, la gratuidad, el empoderamiento... que van más allá de la justicia. Cortina reclama para la ética un estatuto que viene determinado por la autonomía humana a darse sus propias leyes y por la lealtad a esa autonomía. Aprecia que sin lealtad, sin que las razones sean asumidas por la voluntad y por el corazón, la ética estaría sometida sólo a la sanción y quedaría reducida al derecho.

La ethica cordis, por otra parte, hay que situarla en la tradición del reconocimiento recíproco cuyo origen lo encontramos en Hegel y sus Principios de la Filosofía del Derecho, y sobre todo, en los términos que Cortina utiliza, tenemos antecedentes de esta ethica cordis en Apel y Habermas así como en P. Ricoeur y en A. Honnet. Nosotros añadiríamos por nuestra cuenta y riesgo que hay mucho también del pensamiento ético de Lévinas.

Para Cortina un mundo, como ella dice, a la defensiva, que se construye con leyes, contratos, querellas...derecho en definitiva, no es suficiente para conquistar la dignidad humana. Necesitamos la conversión del corazón para sentir los valores y también el valor de cada hombre concreto y es precisamente en el sentir del valor de cada hombre donde radica su autonomía.

Cortina muestra que el modo más humano de vivir no es la ley de la selva y que ni el darwinismo filosófico ni el social pueden explicar el altruismo, la compasión o el cuidado de los débiles. Hechos comprobados desde los tiempos más remotos y que nos diferencian claramente de los animales. Eso le lleva a Cortina a admitir que necesitamos un punto de partida más "realista" en filosofía y en la ética. Hemos de partir no sólo de la racionalidad y el lenguaje, sino también de la corporalidad, de las emociones que presuponen acciones morales, de la cordialidad aunque ello suponga mayor vulnerabilidad. Ese cambio no es otro que la revalorización del mundo, el cambio de los valores materialistas por el de los valores posmaterialistas, el abandono del economicismo, el crecimiento natural limitado frente al crecimiento inmaterial ilimitado, el diálogo, conectar con la naturaleza, celebrar la diversidad, defender la calidad de vida frente a un nivel de vida más alto, incitar a la responsabilidad planetaria frente a la pobreza, desarrollar la empatía porque podemos ser más altruistas que cualquier ser de la naturaleza pero también más crueles.

Ser responsable supone tomar decisiones libres y voluntarias, tener poder y asumir dicho poder y sobre todo un compromiso y un vínculo de confianza con 
otros, vivir en comunidad es estar arraigado en ella y preocuparse por los otros, porque no somos sólo responsables frente a nosotros mismos sino frente a los que nos rodean y por qué no, frente a la humanidad. La libertad, el gran tema de la ética, no está realizada si no superamos la idea de que el individuo puede conquistarla en solitario porque los seres humanos estamos en relación, y la convicción de que en la comunidad política no hay tendencias racionales, que son las que hay que detectar y reforzar. De ahí que lo más valioso en la ética cordial sea el enfrentamiento con el individualismo.

Kant en "La Paz Perpetua" decía que hasta un pueblo de demonios, sin sentido de justicia, estaría interesado en construir un Estado de Derecho. Su propio interés incitaría a su inteligencia a unirse aunque tuviera con ello que renunciar a su libertad: "El problema del establecimiento del Estado tiene solución, incluso para un pueblo de demonios, con tal de que tengan entendimiento"; Por eso, el interés propio no puede construir una ética pública que debe encontrar soluciones justas para los afectados, porque, como ya hemos dicho, la vida se produce entre sujetos que se reconocen mutuamente como seres humanos. La ética trata de resolver conflictos haciendo justicia, lo cual nos hace descartar el individualismo.

Recapitulando, pues, diremos que Cortina perfila en su ética un nuevo sujeto moral a la luz de sus reflexiones y una sociedad civil potente no sólo desde el punto de vista económico o instrumental sino, sobre todo, en el político. Se trata, en definitiva, de reivindicar la obligación con el otro y la responsabilidad social y personal que de ello se deriva. Cortina ve que la autonomía del ser humano, la capacidad de darse a sí mismo las normas tiene dos herramientas principales: la razón y la cordialidad, la razón cordial, porque la ética, como filosofía que es, se puede concebir en palabras de Santayana como una disciplina de la mente y del corazón, una religión laica.

Precisamente abundando en esta idea Cortina recuerda en su artículo publicado el 27 de diciembre de 2014 en El país que aunque la religión civil fuera una solución premoderna ahora tenemos que hablar de justicia social que es la que puede construir soluciones con altura humana. Esta es, por una parte, la denuncia que la razón cordial debe hacer no sólo a la política sino también a cada ser humano que sostiene el estado de cosas tal y como está y por otra parte, también es el reto que tiene planteado la ética cordial en la creación de la justicia social ${ }^{49}$.

49. CORTINA, A. "Religión civil o justicia social", El País, 27-12-2014. 